\title{
O Sofrimento Psíquico e as Novas Modalidades de Relação entre o Normal e o Patológico: Uma Discussão a Partir da Perspectiva Freudiana sobre o Caráter do Psicopatológico
}

\author{
Clara Virginia de Queiroz Pinheiro \\ Isabella Maria Augusto Aguiar \\ Layza Castelo Branco Mendes \\ Universidade de Fortaleza
}

\begin{abstract}
RESUMO
No presente estudo partimos da tese de Ehrenberg, na qual é firmada a idéia de que a atividade clínica, nos dias atuais se estende à totalidade do sofrimento mental, não se restringindo mais aos cuidados com a dimensão patológica da experiência humana. Trata-se da constituição do campo da saúde mental, âmbito em que a psicopatologia se torna um domínio menor. $\mathrm{Na}$ medida em que a prática clínica não se especifica mais pelo caráter patológico de seu objeto, pomos em questão as relações entre o normal e o patológico subjacente à atenção em saúde mental. Dessa forma, iniciamos nossa investigação com o exame dos conceitos do normal e do patológico que marcaram a emergência da atividade clínica. Em seguida, abordamos a psicopatologia freudiana com o objetivo de ressaltar a especificidade do fenômeno psicopatológico em relação a outros tipos de sofrimento humano. Por fim, à luz das formulações freudianas acerca da diferença entre inibição e sintoma, pressupomos a identidade conceitual entre sofrimento psíquico e inibição, analisando as mudanças das relações entre o normal e o patológico que estão por trás das diversas modalidades de sofrimento psíquico adotadas como objeto clínico.
\end{abstract}

Palavras-chave: sofrimento psíquico; normal e patológico; Freud; Ehrenberg; saúde mental.

\author{
ABSTRACT \\ The Psychological Suffering and the New Modalities of the Relationship \\ Between Normal and Pathological: A Discussion from the Freudian \\ Perspective on the Nature of the Psychopathological
}

This study begins from the thesis of Ehrenberg in which the idea is established that current the clinical activity, extends itself to mental suffering overall and is no longer restricted to care with the pathological dimension of human experience. This is the constitution of the field of mental health in which the psychopathology becomes a smaller area. Since the practice was no longer specified by the pathological character of its object, we put into question the relations between the normal and pathological behind the attention on mental health. Thus, we began our research in examining the concepts of normal and pathological that marked the emergence of clinical activity. Then, we look at Freudian psychopathology in order to highlight the specificity of the psychopathological phenomenon in relation to other types of human suffering. Finally, in light of the Freudian formulations about the difference between inhibition and symptom, we assume the conceptual identity between psychological distress and inhibition, analyzing the changes in relations between the normal and the pathological that are behind the various methods of psychological suffering adopted as clinically relevant.

Keywords: psychological suffering; normal and pathological; Freud; Ehrenberg; mental health.

A psicopatologia é, hoje, alvo de mudanças consideráveis no que diz respeito, fundamentalmente, à dimensão prática. Um aspecto preciso chama nossa atenção: o estatuto do sofrimento psíquico que justifica uma ação terapêutica. Situemos nossa questão: A intervenção terapêutica que caracteriza a atividade em saúde mental aplica-se a uma gama heterogênea de fenômenos, que vão desde quadros clínicos classicamente definidos, como as neuroses, a histeria, a neurose obsessiva e as psicoses, até os problemas sempre 
crescentes de toxicomanias, depressões, pânico, e, também, aos estados indefinidos de mal-estar não patológico relativos à condição de infância, adolescência, velhice, vítimas de doenças orgânicas, entre outras. Uma fórmula geral justifica a incorporação à clínica, dessas formas e graus variáveis de infelicidade, - o acolhimento do sofrimento ou, como traduz Ehrenberg (2004, p. 151), "todo sofrimento merece atenção". Trata-se, então, da tomada do sofrimento psíquico em geral como critério dos cuidados clínicos, ou seja, o objeto clínico não é exclusivamente a patologia, mas qualquer sofrimento psíquico. É importante ressaltar, conforme Ehrenberg, que esse agrupamento polimorfo do sofrimento psíquico está estreitamente relacionado à ideia de limitações das vivências pessoais. Consequentemente, a psicopatologia, como terreno teórico-prático restrito à patologia, torna-se uma parte menor de um campo bem mais abrangente denominado de saúde mental. Ocorre, portanto, de acordo com a análise de Ehrenberg (2004), uma extensão horizontal do domínio clínico, que implica o nivelamento entre patologia e sofrimento, perdendo-se, desse modo, a estrutura hierárquica que o caracterizava (p. 151).

Ora, na medida em que o perímetro da atividade clínica se estende ao sofrimento psíquico não patológico, promove-se uma redefinição das relações entre o normal e o patológico, antes definidas pela oposição e diferenciação, fazendo com que o fenômeno patológico perca a sua especificidade em relação ao sofrimento humano. Assim, é nessa linha de raciocínio que situamos o objetivo de nosso estudo, qual seja, investigar as relações entre o normal e o patológico que marcam a atividade clínica na atualidade, considerando que essa equiparação entre patologia e sofrimento psíquico como critério de intervenção terapêutica implica na transformação da relação normal/patológico, "porque esses dois pólos só se definem um em relação ao outro".

Com efeito, "é sempre a totalidade relacional que se modifica, ou seja, não somente a doença e a patologia, mas também a saúde e a normalidade" (Ehrenberg, p. 135). Trata-se, então, de examinar o estatuto do patológico em relação à norma subjacente à prática clínica, partindo da ideia de que na atualidade se esfumaça a definição de patológico como realidade contrária ao normal, uma vez que se adota o sofrimento psíquico como medida de qualificação da saúde mental.

Devemos, todavia, ressaltar que nossa indagação contra as mudanças das formas relacionais entre normal e o patológico não se expressa na margem das reformulações freudianas acerca dos limites entre esses dois pólos. Com efeito, a obra freudiana rompe com a ideia de que o patológico se define pelo seu afastamento da norma. A dimensão psíquica, cuja função consiste, de acordo com a definição de Kristeva (2002), na apropriação do corpo pelo indivíduo, com base na sua condição de ser falante em ligação com o outro, o psicopatológico, depois de Freud (1900/ 1977b), passou a ser entendido como expressão de destino pulsional. A dimensão psíquica, na medida em que assegura, conforme nos esclarece Kristeva (2002), "a responsabilidade do indivíduo animado em relação ao seu corpo, ela o subtrai à fatalidade biológica e o considera como corpo falante" (p. 10). Portanto, a loucura, como doença da alma, forma de expressão psíquica, perde o caráter de alteridade em relação à natureza humana. Esse relativismo não implica, entretanto, no ponto de vista freudiano, o não discernimento da especificidade do patológico diante de outros fenômenos psíquicos, pois é possível estabelecer a diferença entre o sonho e a alucinação, engano e delírio, tabu e obsessão, luto e melancolia, inibição e sintoma. Tais diferenças baseiam-se na irredutibilidade do fenômeno patológico à psicopatologia da vida cotidiana, no que diz respeito a seu caráter regressivo, excessivo e compulsivo e, mais fundamentalmente, a seu estatuto de retorno do recalcado. Essas características do patológico orientaram a clínica freudiana.

Não se pretende neste estudo questionar a continuidade entre o patológico e o sofrimento psíquico subjacente à atividade clínica contemporânea, reivindicando a retomada da condição de alteridade do psicopatológico, como se fez nos tempos "imemoriais", diante de que se justificava o enclausuramento do louco como desprovido de razão, conforme os estudos foucaultianos (1961/1999). Propomos-nos a examinar o sentido do patológico, considerando novas modalidades de relação com a norma. Nossa hipótese, apoiada nas análises de Ehrenberg (2004), é a de que as relações de continuidade entre o normal e o patológico, possibilitada pelo critério do sofrimento, produzem efeitos paradoxais, quais sejam, a "despatologização" do patológico e a "patologização" da vida cotidiana, uma vez que os quadros patológicos propriamente ditos, neurose, psicose, por exemplo, só se constituem como problemas clínicos pelas suas consequências no processo de desenvolvimento e realização do indivíduo, assim como qualquer outro obstáculo para realização pessoal se torna uma preocupação médica. Assim, no campo da saúde mental, a noção de sofrimento psíquico não adquire importância clínica em relação à ideia de normalidade, como parâmetro 
de saúde, mas à ideia de bem-estar, como parâmetro de qualidade de vida, a qual se constitui em norma médica.

Nosso trabalho se desenvolverá a partir do estudo dos conceitos e das relações entre o normal e patológico, com base nas pesquisas de Canguilhem e Foucault sobre os fundamentos do saber médico. Em seguida, examinaremos a gênese freudiana da noção de psicopatológico, bem como suas formulações acerca da diferença entre sintoma e inibição para, finalmente, investigarmos, à luz das análises de Ehrenberg, o caráter não patológico do mal-estar na contemporaneidade.

\section{Sobre as relações entre o normal e o patológico}

A medida de qualificação da saúde e da doença em termos de normal e patológico é característica da medicina moderna, conforme os estudos de Foucault (1963/1994). Vejamos suas afirmações:

De um modo geral, pode-se dizer que até o final do século XVIII a medicina referiu-se muito mais à saúde do que à normalidade; não se apoiava na análise de um funcionamento - regular - do organismo para procurar onde se desviou o que lhe causa distúrbio, como se pode restabelecê-lo; referia-se mais a qualidades de vigor, flexibilidade e fluidez que a doença faria perder e que se deveria restaurar. (p. 39)

Portanto, a dualidade entre normal e patológico como princípio ordenador da atividade clínica está diretamente ligada à ideia do funcionamento regular do organismo como realidade própria do fenômeno da doença. Dito de outro modo: o normal e o patológico designam o grau de funcionalidade orgânica. Nessa perspectiva, o patológico se define como negatividade, desse modo, como impossibilidade do padrão normativo do organismo. Essa relação antagônica entre saúde e doença concerne à realidade orgânica, a qual se expressa como polaridade entre a vida e a morte. Em outros termos, a vida é movimento contrário à morte. A relação entre normal e patológico é estabelecida como oposição, assim como a morte se opõe à vida. A morte é, portanto, a grande referência em relação à qual o patológico se especifica como fenômeno orgânico.

Podemos dizer, então, que o patológico assume a conotação de negatividade, porém, uma negatividade constitutiva da vida. Ora, na medida em que o patológico se define como fenômeno relativo ao funcionamento orgânico, perdendo assim o status de realidade originária, deixa de ser apreendido como outra natureza ou como contra-natureza. Em outras palavras, a con- cepção da vida como realidade orgânica e espaço próprio do normal e do patológico, faz com que todo fenômeno corporal seja apreendido em termos das regularidades biológicas, ou seja, nada é exterior às leis naturais.

Com efeito, a realidade biológica se caracteriza pela diversidade, variação e mutabilidade. Nessa perspectiva, torna-se possível o desencantamento pelo estranho, o que implica a ruptura com a sensibilidade social nos séculos XVI-XVIII, conforme indicações de Courtine (2005, p. 373). Trata-se do encanto causado pelos monstros, indivíduos anatomicamente deformados, os quais escapavam aos critérios de identificação do natural e do humano, sendo assim apreendidos como inumanos. A figura do monstro delineia-se pela sua diferença extrema, rara, única e absoluta, como nos esclarece Foucault (1999) em seus estudos sobre genealogia do anormal, pois, o monstro é aquele que combina o impossível e o proibido. Quem são os monstros? Quais limites naturais e sociais ultrapassam? Os monstros são aqueles que embaralham os critérios de identificação do humano. Por exemplo, a diferença entre os sexos que o hermafrodita confunde, assim como os siameses perturbam o critério de individualidade corporal, fundindo em um mesmo corpo duas cabeças ao mesmo tempo, embaralham as fronteiras de diferenciação das espécies, combinando homem e animal. Portanto, o monstro é o estranho em relação às leis da natureza e, por isso mesmo, estranho à ordem social, como aberração natural se torna inapreensível pelas leis sociais. Em outras palavras, o monstro é aquele que embaralha o sistema de classificação dos seres vivos e o sistema de regulação das relações sociais. Num lugar diferente está o anormal, indivíduo comum, banal, cotidiano, cuja limitação orgânica o torna inapto para corresponder às exigências do meio, tendendo a sucumbir.

Portanto, a dualidade entre o normal e o patológico designa diferença e oposição das regularidades funcionais e não descontinuidade ontológica. Entretanto, essa diferença funcional, de acordo com Canguilhem (1966/1995), não se define por critérios quantitativos, no sentido de faltas ou excessos, mas de estados qualitativamente opostos. Nessa perspectiva, o patológico é um acontecimento polêmico, problemático. $\mathrm{Na}$ verdade, podemos dizer, é a própria expressão do mal, na medida em que consiste na impossibilidade de sobreviver frente às expectativas do meio. Assim nos esclarece Canguilhem: "o patológico implica em pathos, sentimento direto e concreto de sofrimento e de impotência, sentimento de vida contrariada". (Cangui- 
lhem, p. 106). E acrescenta: "Mas o patológico é realmente o anormal". (p. 106). Desse modo, o patológico se caracteriza pelo padecimento, pela impossibilidade e tem o sentido de negatividade, devendo, a todo custo, ser combatido. Nessa perspectiva, o patológico se caracteriza como o oposto da saúde. Contudo, devemos asseverar, conforme os ensinamentos de Canguilhem, que o normal não designa uma realidade essencial, portanto única, do funcionamento do organismo, mas constitui uma forma específica, circunstancialmente favorável, de lidar com as agruras do meio, possibilitando a manutenção e realização da vida. Por conseguinte, Canguilhem (1966/1995, p.96) desconsidera a identidade entre saúde e normalidade, pois saúde é mais do que estar em conformidade com a norma, é normatividade, ou seja, "é o que institui as normas". Assim, saúde é o movimento de excelência da vida.

Desse modo, não incorremos em erro ao afirmar que, referida a medida de qualificação em termos de normal e patológico, a atividade clínica pode se caracterizar pela sua tendência em direção ao polo patológico, visando à cura, ao tratamento, enfim, nesse sentido, pode ser definida como atividade terapêutica. Inclinando-se para o pólo da normalidade, a intervenção clínica orienta-se pela finalidade de instaurar uma norma, tendo em vista determinadas expectativas do meio. Outrossim, a atividade clínica pode tender para a transposição da correspondência à norma e visar à normatividade, caracterizando-se como promotora de saúde, isto é, potencializadora das capacidades orgânicas; condicionadora de uma individualidade resultante da invenção de normas de realização e, não apenas, da submissão à norma possível.

Considerando as formulações acerca da especificidade da clínica contemporânea, anteriormente mencionadas, daremos continuidade ao nosso estudo circunscrevendo o domínio da psicopatologia freudiana, para daí demarcar as mudanças das relações entre o normal e o patológico.

\section{A psicopatologia freudiana e a questão do normal e do patológico}

Nosso ponto de partida é a tese de que as formulações freudianas em torno do padecimento psicopatológico se especificam quando tomamos como referência a medicina orgânica, que inaugura o campo epistemológico próprio da clínica moderna, de acordo com os estudos de Foucault (1963/1994). Dessa forma, situamos a clínica psicanalítica no campo episte- mológico fundado pela biologia e anatomia patológica, consequentemente marcada pelas relações entre o normal e o patológico.

Com efeito, Freud (1893/1977a) estabelece a natureza das paralisias histéricas com suporte em um estudo comparativo com as paralisias orgânicas, fundando, assim, o domínio próprio do psicopatológico. Levando em conta os aspectos que fazem a distinção entre os sintomas histéricos e as paralisias cerebrais, Freud expressa, seguramente, que, no primeiro caso, contrariamente ao segundo, não há dependência com lesões anatômicas, e faz a seguinte ponderação: "a histeria se comporta como se anatomia não existisse, ou como se não tivesse conhecimento desta". (p. 234). Assim, de acordo com o posicionamento freudiano, na histeria, o que condiciona a paralisia do órgão ou seu disfuncionamento, por exemplo, do braço, é uma modificação da "ideia de braço". (p. 236). Tal modificação, portanto, não diz respeito ao membro superior, braço, com todos os desdobramentos anatômicos, mas à ideia. Em outros termos, a paralisia do braço está relacionada à dissociação da ideia de braço do conjunto de ideias que constituem o sentido do "eu" do indivíduo, ou seja: "a concepção do braço não consegue entrar em associação com as outras ideias constituintes do ego, do qual o corpo da pessoa é parte importante". (p. 236).

Dessa forma, Freud (1893/1977a) apresenta a tese da realidade psíquica por trás dos fenômenos histéricos, irredutíveis à anatomia patológica. Remetidos à realidade psíquica, os sintomas neuróticos devem ser entendidos como representações que são patológicas pelo fato de estarem apartadas das cadeias associativas constitutivas da experiência subjetiva. Eis, então, o ponto fundamental acerca do patológico em Freud: a relação entre sintoma e linguagem. Em outras palavras, o sintoma psíquico, como a paralisia histérica, diferentemente da paralisia cerebral, remete à dimensão do sentido da experiência subjetiva, quer dizer, à referência em relação à qual a existência humana (pelo menos na modernidade) adquire sua razão de ser.

Podemos dizer mais precisamente que Freud situa o psicopatológico como fenômeno diretamente relacionado à finalidade da experiência subjetiva. Daí a tese freudiana, exposta na conferência Psicanálise e Psiquiatria (1914/1977c, p. 294), segundo a qual não há ação humana ao acaso, mesmo uma ação banal, por exemplo, um pequeno descuido, um esquecimento destituído de qualquer valor, no seu entender "não é uma ação casual, mas teve um motivo, um sentido e uma intenção, que se localiza num contexto mental 
específico e que informa, mediante uma pequena indicação, acerca de um processo mental mais importante". Portanto, o sintoma psíquico é constitutivo de um sentido, que não se apresenta por meio de ideias claras e distintas.

A realidade psíquica deve ser entendida em sua dimensão semântica, para usar os termos de Gabbi Jr. (1992), e consiste de uma organização complexa e heterogênea das várias formas de inscrição da experiência de prazer, princípio da subjetividade, que envolve fonte de satisfação pulsional, objeto e meios de satisfação. Tais formas de inscrição definem as diferentes fases da história psicossexual do sujeito. Considerando então o caráter semântico do funcionamento do aparelho psíquico, podemos dizer, em conformidade com os estudos de Gabbi Jr., que os fenômenos patológicos são perturbações na tradução das referências de uma fase para outra da história psicossexual, o que acarreta perda das relações de sentido da experiência subjetiva. Tal falta de sentido é o que caracteriza propriamente o sintoma, o qual se torna inteligível após o restabelecimento de suas vinculações com a história do sujeito.

Vejamos a análise Freud (1914/1977c, p. 297) de um caso de neurose obsessiva: Uma senhora que se atormentava com um ciúme intenso do marido, e que, ao mesmo tempo, o reconhecia como injustificável. Freud mostra o caráter patológico do ciúme, refratário a qualquer argumento que o inviabilize, inclusive da própria senhora, acerca da fidelidade do digníssimo esposo. Diante de tal ideia incompatível com a realidade, portanto, aparentemente absurda, o autor se questiona: "De onde mais ter-se-ia originado?". Após um curto período de análise, ele configura o sentido do sintoma, deduzindo que ciúme era a metamorfose do desejo inconcebível da senhora por seu genro, que, por sua vez, já era uma transformação do vínculo erótico mais profundo com a filha. Tal desejo inconsciente exercia uma pressão intolerável, forçando sua expressão; essa satisfação só poderia efetivar-se mediante de radicais deslocamentos, substituições, de modo que seu sentido original se tornasse completamente inapreensível. Esse trabalho de metamorfose semântica constitutivo do ciúme da nobre senhora consistiu da transformação da culpa em acusação (em vez de trair, ser traída), da projeção do desejo do sujeito (o amor pelo jovem) em sua imagem especular, o marido, e na substituição do objeto de desejo (a filha pelo genro, o genro pela amante). Nesse caso, conforme analisa Freud (1914/1977c, p. 299), o sintoma (expressão de desejo) funcionou como "uma compressa fria em uma ferida ardente", na medida em que serviu como meio de satisfação de uma excitação implacável, mesmo ao preço de um doloroso estranhamento da senhora consigo mesma.

Desse modo, Freud se afasta da tradição humanista, conforme os estudos de Pinheiro, Lima e Rios (2007) sobre a arqueologia da psicanálise, posto que desloca da consciência o princípio da experiência de si, destitui a consciência da função significante e totalizadora da subjetividade. Não se trata, então, de pensar o psicopatológico freudiano, como poderíamos ser levados a pensar, a exemplo do que admite a psicopatologia fenomenológica de Jaspers (1913/1979), como alterações das formas de apreensão de si e do mundo que caracterizam a consciência, mas consiste do fato de certas representações estarem excluídas da cadeia associativa constitutiva do ego, e, exatamente por isso, se expressando de forma patológica. Ora, em Freud, o sentido do eu não é idêntico ao eu fenomenológico da consciência de si implicado numa vivência empírica. Podemos dizer, considerando as formulações de Freud (1900/1977b), que a questão do sentido do eu não se refere ao vivido, mas ao representado, aos registros da experiência, cuja ordenação, economia e dinâmica, estão condicionadas às relações entre prazer e interdição. Portanto, nunca é demais ressaltar que o psicopatológico freudiano se explica pela metapsicologia e não pela fenomenologia.

Na concepção freudiana, o princípio do prazer e as possibilidades de realização constituem o ponto nuclear da experiência subjetiva. Mais uma vez, devemos esclarecer que o prazer na teoria psicanalítica, como ressalta Kehl (2007), não diz respeito ao encontro empírico entre o indivíduo e o seu objeto de desejo, mas à relação entre um quantum pulsional e a representação do objeto de satisfação. Trata-se, precisamente, da representação da pulsão, ou seja, de sua simbolização. Este é o sentido de prazer freudiano.

Retornemos, então, às formulações do autor em causa sobre a natureza do fenômeno patológico, situando a questão de saber sobre a especificidade do patológico tal como Freud sustenta, considerando as diferenças entre sintoma e inibição, estabelecidas no texto Inibições, sintoma e ansiedade (1926/1977d). Retomaremos, então, o tema sobre a reviravolta nas relações entre o normal e o patológico subjacente a clínica contemporânea.

Assinalamos, há pouco, que a questão essencial da concepção freudiana do sofrimento psíquico é a referência à dimensão simbólica. A constituição da di- 
mensão simbólica está diretamente relacionada à condição de desamparo originária da experiência humana. A função psíquica consiste na condução da excitação pulsional ligando-a ao objeto de satisfação, instituindo seu caráter ideativo. A ligação entre excitação e representação de objeto marca a ruptura com o estado de desamparo absoluto caracterizado pela irrupção de energia pura, sem representação. A simbolização obedece a uma lei primordial, qual seja, a proibição ao incesto, que assume toda sua força na ameaça de castração. Nessa linha de raciocínio, o psicopatológico diz respeito a uma forma drástica, excessiva, de interditar a insurgência de uma excitação ligada a certas representações objetais, interditadas pelo mecanismo do recalcamento.

Portanto, o mecanismo de recalcamento é um elemento essencial da especificação do patológico. Em virtude do recalcamento, o sintoma se constitui como substituto da satisfação pulsional recalcada. Entretanto esse rebaixamento da satisfação a um sintoma, como assevera Freud (1926/1977d), não implica experiência prazerosa, mas compulsão. Como substituto da representação recalcada, o sintoma se forma por meio de um processo tortuoso e complexo de metamorfose da ideia original, mediante deslocamentos, substituições e projeções, tanto do impulso quanto do representante, de tal modo que se torna irreconhecível (daí a especificidade do trabalho de análise). Como substituto do impulso recalcado o sintoma é uma formação localizada fora do ego, gozando, assim, como afirma Freud (1926/1977d, p. 119), do "privilégio da extraterritorialidade." Além disso, o sintoma não deixa de exercer uma pressão, buscando satisfação. Desse modo, a formação do sintoma decorrente do recalcamento obriga o ego a permanecer, incansavelmente, na posição defensiva, agora, não somente contra o impulso inconsciente, mas contra o seu substituto. A formação do sintoma implica a divisão da subjetividade, engendrada pelo conflito entre duas grandes forças: de um lado, a tendência ao prazer, e, de outro, a interdição. Dessa forma, o cenário próprio da produção do sintoma é a força, a defesa, luta que implica dispêndio de energia, mecanismos diversos e instâncias diferentes.

O caráter patogênico do sintoma está diretamente relacionado ao fato de que sua formação é a solução para retirar o ego de uma situação de perigo devastadora, que podemos definir como invasão pulsional. Nessa perspectiva, o sintoma consiste da transformação necessária da economia psíquica diante do risco da dissolução causada pela energia livre. A força necessária para que o ego resista à invasão pulsional é a angústia, um sentimento de desprazer intolerável, que obriga o ego a reagir contra o domínio pulsional. Assim, o sintoma implica a transformação patológica do psiquismo para dar conta do perigo da castração. Portanto, o traço patológico da formação do sintoma consiste na sua relação com uma circunstância de perigo desorganizadora e, por isso mesmo, causadora de angústia extrema.

Daí nossa tese, estabelecida no início do artigo, de que Freud aponta a relação de oposição entre o normal e o patológico, pois, o sintoma, como substituto do recalcado, assume o lugar central da organização psíquica. Desse modo, podemos caracterizar a clínica psicanalítica como campo hierárquico no qual o patológico se constitui como critério de intervenção.

Assim, não é por acaso que Freud (1926/1977d) estabelece comparação entre sintoma e inibição. A inibição, no seu entender, é um fenômeno estreitamente relacionado ao exercício da função. Há de se reconhecer, pois, das limitações das funções egoicas, como inibição sexual, motora, alimentar, profissional, entre tantas outras, as quais não são em si mesmas patológicas, assumindo o sentido patológico quando condicionadas ao processo defensivo do ego, como meio para evitar a angústia concernente ao desamparo. Exemplo disso seria a inibição de sair de casa, que complementa, muitas vezes, os quadros fóbicos. Somente neste contexto, conforme indicações freudianas, a inibição tem o caráter patológico.

Para concluir, talvez, não seja incorreto reconhecermos uma relação de identidade entre inibição e sofrimento psíquico não patológico. Se assim for, podemos dizer, considerando as análises de Ehrenberg (2004), sobre a reviravolta das relações entre o normal e o patológico implicada na atividade clínica, (que toma como alvo da intervenção o sofrimento psíquico sem patologia), que a inibição psíquica se torna hoje o legítimo critério para uma ação clínica. Sobre os determinantes dessa reviravolta baseada na importância que a inibição psíquica adquire, constituindo-se o grande objeto da preocupação médica, podemos destacar dois posicionamentos: de um lado, a visão, Kehl (2007), ao afirmar que as explicações neurocientíficas do sofrimento psíquico como efeito de transtorno cerebral, levam à transformação da subjetividade, caracterizada pela redução da vida psíquica às funções do ego, o que implica a recusa da dimensão pulsional; de outra parte, o ponto de vista, apresentado por Ehrenberg (2004), de acordo com o qual essa "medicalização" do sofrimento não patológico decorre da mudança da regra social, passível de ser caracterizada 
pela substituição da lei da castração pela injunção à autonomia, implicando a realização pessoal relativamente à restrição das funções do ego que representaria o maior obstáculo.

O exame dessas teorias extrapola o limite do presente estudo, que visa ressaltar as relações dominantes do normal e do patológico subjacente à ideia de sofrimento psíquico como critério da prática psicoterapêutica na atualidade. Entretanto, devemos ressaltar o subjacente a essas explicações, ou seja, a relação estreita entre sofrimento psíquico, normal e patológico e a sociedade contemporânea.

\section{REFERÊNCIAS}

Canguilhem, G. (1995). O normal e o patológico (4 ${ }^{\mathrm{a}}$. ed.) (M. T. R. C. Barrocas, Trad.). Rio de Janeiro: Forense Universitária. (Originalmente publicado em 1966)

Courtine, J. J. (2005). Le corps inhumain. Em Corbin, A., Courtine, J-J., \& Vigarello, G. (Org.). Histoire du corps: Vol. I. Paris: Seuil.

Ehrenbeg, A. (2004, maio). Les changement de la relation normal - pathologique. Em Revue Esprit. pp.133-156.

Foucault, M. (1999). História da loucura (6 ${ }^{\text {a }}$. ed.) (J. T. Coelho Netto, Trad.). São Paulo: Perspectiva. (Originalmente publicado em 1961)

Foucault, M. (1999). Les anormaux - Cours au Collège de France (1974-1975). Paris: Gallimard Le Seuil.

Foucault, M. (1994). O nascimento da clínica (4 ${ }^{\mathrm{a}}$. ed.) (R. Machado, Trad.). Rio de Janeiro: Forense Universitária. (Originalmente publicado em 1963)

Freud, S. (1977a). Alguns pontos para um estudo comparativo das paralisias motoras orgânicas e histéricas (J. Salomão, Trad.).
Em J. Strachey (Org.), Edição Standard Brasileira das Obras Psicológicas Completas de Sigmund Freud (Vol. 1, pp. 219239). Rio de Janeiro: Imago. (Original publicado em 1893)

Freud S. (1977b). A interpretação de sonhos (J. Salomão, Trad.). Em J. Strachey (Org.), Edição Standard Brasileira das Obras Psicológicas Completas de Sigmund Freud (Vol. 5, pp. 543665). Rio de Janeiro: Imago. (Original publicado em 1900)

Freud, S. (1977c). Psicanálise e psiquiatria (J. Salomão, Trad.). Em J. Strachey (Org.), Edição Standard Brasileira das Obras Psicológicas Completas de Sigmund Freud (Vol. 16, pp. 289303). Rio de Janeiro: Imago. (Original publicado em 1914)

Freud, S. (1977d). Inibições, sintomas e ansiedades (J. Salomão, Trad.). Em J. Strachey (Org.), Edição Standard Brasileira das Obras Psicológicas Completas de Sigmund Freud (Vol. 20, pp. 95-201). Rio de Janeiro: Imago. (Original publicado em 1926)

Gabbi Jr, O. F. (1992). Alice e a metapsicologia: A psicanálise como teoria do contra-senso. Campinas: Unicamp.

Jaspers, K. (1979). Psicopatologia geral. (8a. ed.) (S. P. Reis, Trad.). Rio de Janeiro: Atheneu. (Original publicado em 1913)

Khel, M. R. (2007). Elogio ao medo. Em A. Novaes (Org.), Ensaios sobre o medo (pp. 89-110). São Paulo: Edições SENAC.

Kristeva, J. (2002). As novas doenças da alma (J. A. D. Melo, Trad.). Rio de Janeiro: Rocco.

Pinheiro, C. V., Lima, C., \& Rios, N. (2007). A concepção foucaultiana de antropologia-humanista como ponto de partida para uma arqueologia da psicanálise. Revista Aulas, 3 [Dossiê Foucault]. Retirado em 10 de agosto de 2007, de http://www.unicamp.br/ aulas/pdf3/06.pdf.

Recebido: $14 / 01 / 2008$ Última revisão: 02/12/2008 Aceite final: $10 / 12 / 2008$

\section{Sobre as autoras:}

Clara Virginia de Queiroz Pinheiro: Doutorado em Saúde Coletiva IMS-UERJ, Professora Titular do Programa de Mestrado em Psicologia-Unifor. Endereço: Joaquim Nabuco, 2769/902, Dionísio Torres. Fortaleza - CE - Endereço eletrônico: claravirginia@unifor.br

Isabella Maria Augusto Aguiar: Mestre em Psicologia - Unifor - Endereço: Rua Coronel Linhares, 777/801. Meirelles - 60170-240 Forteleza - CE - Endereço eletrônico: isabellaaguiar@ fortalnet.com.br

Layza Castelo Branco Mendes: Mestre em Psicologia-Unifor, Professora Substituta do Curso de Psicologia-UECE. Endereço: Rua Min. Eduardo Ellery Barreira, 29/702a, Cocó, 600811-391 - Endereço eletrônico: layzacb@ yahoo.com.br. 